\title{
Altitudinal variation in the volatile constituents of Cymbopogon flexuosus from Uttarakhand region of Himalaya
}

\author{
Anju Bhatnagar \\ D.B.S. (P.G.) College, Dehradun-248001 (Uttarakhand), India \\ E-mail: dbsanju2014@gmail.com
}

\section{Article Info}

DOI:10.31018/jans.v11i2.1988

Received: January 9, 2019

Revised: March 23, 2019

Accepted: April 8, 2019

\begin{abstract}
The essential oils of Cymbopogon flexuosus (lemon grass) of the family Poaceae collected from different altitudes of the Uttarakhand region of Himalaya were subjected to detailed GC/MS analysis in order to determine the variation of concentration in their constituents. The GC/MS analysis led to the identification of 29 constituents forming 90.62 to $93.58 \%$ of their total oil content. The major constituents were citral, geraniol, citronellol, citranellal, linalool, borneol, $\beta$-myrcene limonene, $\beta$-caryophyllene, camphene, $\gamma$ cadinene, $\alpha$-terpineol, neryl acetate and heptenone. Plants collected from $450 \mathrm{~m}$ altitude afforded citral $(74.58 \%)$ [a isomeric mixture of geranial and nearl] as a major constituents whereas only a less percentage of citral $(64.21 \%, 68.29 \%)$ was found in the plants collected from two other altitudes i.e $250 \mathrm{~m}$ and $1000 \mathrm{~m}$ respectively. The geraniol, camphene and neryl acetate were obtained in a high concentration form the plants collected at $250 \mathrm{~m}$ altitude but in the plant from two other altitudes, it was found only in less proportion. Similarly, $y$-cadinene, a-terpineol and camphene were the major constituents of plants at $1000 \mathrm{~m}$ altitude but in other plants it was detected in very low concentration. Since, the concentration of plant constituents affected by altitude and season, medicinal properties of such plants and their use in biological application would vary accordingly.
\end{abstract}

Keywords: Altitudes, Citral, Cymbopogon flexuosus, Monterpene, Poacease

\section{INTRODUCTION}

Cymbopogon is the one of most important essential oil yielding genera of family Poaceae. Lemongrass, palmarosa and citronella are the important essential oil yielding members. Essential oils have played an important role in human life, so much so that they have become indispensable in the production of perfumes, cosmetics, medicines, food preparation and as a starting material for the synthesis of various other compounds. (Badoni et al., 2010). The essential oils are concentrated, hydrophobic liquid containing volatile aroma compounds of plants, which are called aromatic herbs or aromatic plants. They are also known as volatile or ethereal oils, or simply as the oil of the plants from which they are derived, such as camphor oil, peppermint oil, lemon grass oil, etc. About 8000 flowering plant species grow in western Himalaya rich in genetic diversity of medicinal and aromatic plants (Rao, 1994). The Genera Cymbopogon comprises about 140 species worldwide, out of which 45 species have been reported to occur in India. The members of the genus Cymbopogon occur abundantly in tropics and sub tropics regions of Asia, Africa and America with a regular distribution ranging from mountains and grassland to arid zones (Soenarko,1997; Bor,1960, Khanuja et al.,2005, Padalia et al.,2011). Cymbopogon species display wide variation in morphological attributes and essential oil composition at inter and intra specific level over the years (Sangwan et al.,2001) The most common economic species viz., C. winterianus, $C$. flexuosus, C. martinii var. motia and sofia, C. nardus var. nardus, C. citratus, C. pendulus, $C$. warancusa, C. khasianus produce different types of essential oils such as palmarosa oil, lemongrass oil, citronella oil, ginger grass or rusa oil of commercial interest (Gupta and Jain, 1978;Mathela, et al.,1986; Kumar, et al.,2000).

C. flexuosus is tall, fast growing, lemon scented, perennial grass reaching a height of $1.5 \mathrm{~m}$. It has distinct, dark green foliage and also produces seed. Lemon grass prefers tropical and subtropical climate, it grows well at a temperature range of $10^{\circ} \mathrm{C}$ to $33^{\circ} \mathrm{C}$ and needs enough sunshine for the development of oil in the plant. The grass is sensitive to cold weather and cannot withstand in frost. Essential part of plant is stalks and leaves. The essential oil is extracted from fresh plant material by means of hydrodistillation (Lawrence, 1988).

The essential oils from Cymbopogon species such as lemongrass, palmarosa and citronella contains 
a wide variety of cyclic and acylic monoterpene such like citral(3,7-dimethyl 2,6-octadienal; a mixture of two isomer geranial and neral)is used in vitamin $A$ and ionone synthesis.. Other constituent like geraniol and its ester, citronellol and citronellal are important perfume materials. Several Cymbopogon species possessed significant anthelmintic, anti inflammatory, analgesic, antiageing, pesticidal, antimicrobial, mosquito repellant and larvicidal activities and thus, are used in native medicine for curing a number of diseases (Rao, 1997). Studies on the oil composition of various Cymbopogon species have been carried out time to time, who reports geraniol, geranyl acetate, citral, limonene, elemecin, monoterpene alcohols and sesquiterpenes as the major constituents in their essential oils (Kulkarni, et al., 1992; Khanuja, et al., 2005; Rao,et al., 2009; Verma, et al.,2009). The commercial aspects of the essential oils of these aromatic grasses and their cultivars prompted us to carry out detailed comparative terpenoid composition of cultivated species $C$. flexuosus in Northern part of India.

\section{MATERIALS AND METHODS}

Plant material: The aerial parts of C.flexuosus were collected at CIMAP Centre, Pantnagar; CAP Centre, Selaqui Dehradun and Horticulture College, Tehri having altitude $250 \mathrm{~m}, 450 \mathrm{~m}$ and above $1000 \mathrm{~m}$ above $\mathrm{msl}$ respectively were collected from different altitudes of the Uttarakhand in September, 2016 Himalayan region and duly identified by Botany Department, Forest Research Institute, Dehradun. After identification the voucher specimens of $C$. flexuosus (A-1 to A-3) were kept in the herbarium of D.B.S (P.G) College Dehradun, Uttarakhand (India).

Essential oil extraction: The essential oil was extracted from $100 \mathrm{gms}$ if fresh plant material in 3 replicates by hydro-distillation method using Clevenger apparatus for 3 hours. The essential oil evaporated together with vapors and collected as oil drop after condensation into a closed tube attached to Clevenger apparatus. The essential oil was separated from an aqueous phase using a separating funnel. The essential oil was dried over anhydrous $\mathrm{Na}_{2} \mathrm{SO}_{4}$ and stored in sealed vials under refrigeration for further analysis. Oil content in terms of oil percentage was calculated as the mean of 3 samples. The oil yield was calculated on the basis of fresh weight of the material $(\mathrm{v} / \mathrm{w})$. ( Kulkarni, et al., 2003; Padalia, et al.,2011)

GC-MS analysis: The GC-MS analysis of the oils were carried out by GC Perkin Elmer Clarus 500 with a mass spectrometer PerkinElmer Clarus 500 fitted with an RTX-5 capillary column $(60 \mathrm{~m}$ $\times 0.32 \mathrm{~mm}$ i.d., film thickness $0.25 \mu \mathrm{m}$ ). The oven column temperature vary from $60^{\circ} \mathrm{C}-210^{\circ} \mathrm{C}$, programmed at $3^{\circ} \mathrm{C} / \mathrm{min}$, with initial and final hold time of 2 min, using $\mathrm{He}$ as carrier gas at $10 \mathrm{psi}$ constant pressure, a split ratio of 1:50, an injection size of $0.02 \mu \mathrm{L}$ neat, injector, transfer line and source temperatures were $210^{\circ} \mathrm{C}$; ionization energy $70 \mathrm{eV}$; mass scan range 40-450 amu.

Identification of constituents: The Identification of constituents was done on the basis of retention time, Retention Index [RI, determined with reference to homologous series of n-alkanes $\left(C_{9}-C_{26}\right.$, Polyscience Corp., Niles IL) under identical experimental condition], co-injection with standards referencecatalogue (Aldrich and Fluka), mass spectra library search (NIST/EPA/NIH version 2.1 and Wiley registry of mass spectral data 7th edition) and by comparing with the mass spectral literature database (Adams,1995; Davies, 1990). The relative amounts of individual components were calculated based on GC peak areas without using correction factors.

\section{RESULTS}

The essential oil extracted from fresh aerial parts of three cultivars of C.flexuosus species viz. Cauvery, Krishna and Chirharit by hydrodistillation method, using a Clevenger apparatus. The distilled oils were dried over anhydrous sodium sulphate and keep in vial at $4^{0} \mathrm{C}$ for further analysis. The composition of essential oils were analyzed by GC-MS. The GC/MS analysis led to the identification of 28-29 constituents forming 92.1 to $97.5 \%$ of their total oil composition with monoterpenoids (78.3 to $88.9 \%$ ) as most exclusive constituents. The comparative results showed considerable variation in qualitative and quantitative compositions of major constituent of essential oils form three different cultivars of the studied C.flexuosus (Table1).

The cultivars of $C$. flexuosus were rich in citrals (comprised of neral and geranial) with highest proportion in cv.Krishna $(74.58 \%)$ followed by chirharit $(71.00 \%)$ and Cauvery $(68.60 \%)$. The essential oil extracted from C. flexuosus var. Krishna is taken for study of altitudinal variation. The yield of essential oil of $C$. flexuosus harvested in month of September was $0.5-0.7 \%$ for fresh herbage weight. The yield of oil fluctuates greatly with the season, the condition of plant material, its moisture content and age of planting.

The GC/MS analysis of the essential oil led to the identification of 29 constituents. The major constituents present in C.flexuosus plant collected in September month from $250 \mathrm{~m}$ altitude were camphene $(3.89 \%)$, limonene $(1.04 \%)$, citral $\{$ (isomeric mixture of geranial $(34.65 \%)$ and neral $(29.56 \%)\}$, borneol $(1.07 \%)$, geraniol $(3.82 \%)$, neryl acetate $(1.75 \%)$, Caryophyllene oxide $(1.03 \%)$. The plants collected from $450 \mathrm{~m}$ altitude contained linalool (1.65\%), geranial (40.29\%), neral (34.29\%) $\beta$ Caryophyllene(1.14\%), and Caryophyllene oxide $(1.10 \%)$ as a major constituents. $Y$-Cadinene $(2.01 \%)$, mentha $(1.02 \%)$, a-terpineol(2.45\%), and 
Bhatnagar, A. / J. Appl. \& Nat. Sci. 11(2): 263- 266 (2019)

Table 1. Major components of different cultivars of C.flexuosus.

\begin{tabular}{llccc}
\hline S.N. & Major compounds & \multicolumn{3}{c}{ Concentration (\%) } \\
\cline { 3 - 5 } & & Cauvery & Krishna & Chirharit \\
\hline 1. & Neral & 31.2 & 34.29 & 31.4 \\
2. & Geranial & 37.4 & 40.29 & 39.6 \\
3. & Geraniol & 1.9 & 1.47 & 2.7 \\
4. & Limonene & 0.5 & 0.92 & 0.9 \\
\hline
\end{tabular}

Table 2. Chemical composition of essential oil of C.flexuosus harvested in September, 2016 from three altitudes of Uttarakhand.

\begin{tabular}{|c|c|c|c|c|c|}
\hline \multirow[b]{2}{*}{ S.N. } & \multirow{2}{*}{$\begin{array}{l}\text { Retention } \\
\text { Indices }\end{array}$} & \multirow[b]{2}{*}{ Name of constituents } & \multicolumn{3}{|c|}{ Area , \% } \\
\hline & & & $\begin{array}{l}\text { Pantnagar } \\
250 \mathrm{~m}\end{array}$ & $\begin{array}{l}\text { Dehradun } \\
450 \mathrm{~m}\end{array}$ & $\begin{array}{l}\text { Ranichuri } \\
<1000 \mathrm{~m}\end{array}$ \\
\hline 1. & 10.00 & Tricyclene & 0.52 & -- & 0.33 \\
\hline 2 & 10.48 & $\alpha$-Pinene & 0.83 & 0.74 & 0.42 \\
\hline 3. & 10.52 & $\beta$-myrcene & 0.39 & 0.42 & 0.33 \\
\hline 4. & 11.13 & Camphene & 3.89 & 2.01 & 2.47 \\
\hline 5. & 12.70 & Hept-5-en-2 one & 2.58 & 1.98 & 0.85 \\
\hline 6. & 14.42 & Limonene & 1.04 & 0.92 & 0.51 \\
\hline 7. & 14.44 & $\beta$-ocimene & 0.01 & 0.05 & 0.06 \\
\hline 8. & 14.52 & Eucalyptol & 0.83 & -- & -- \\
\hline 9. & 14.77 & a-Pinene & 0.71 & 0.63 & 0.35 \\
\hline 10 & 15.18 & Carven & 0.04 & 0.14 & -- \\
\hline 11 & 16.19 & Pentyl propyl ketone & 0.9 & 1.29 & 1.27 \\
\hline 12 & 16.97 & Citronellal & 0.31 & 0.44 & 0.22 \\
\hline 13 & 17.29 & Linalool & 1.69 & 1.65 & 1.41 \\
\hline 14 & 19.10 & Chrysanthemol & 0.67 & -- & 0.53 \\
\hline 15 & 19.92 & Borneol & 1.07 & 1.01 & 0.33 \\
\hline 16 & 20.33 & Verbenol & 1.49 & 1.7 & 1.59 \\
\hline 17 & 20.85 & a-terpineol & 0.34 & 0.35 & 2.45 \\
\hline 18 & 21.99 & Mentha & -- & 0.44 & 1.02 \\
\hline 19 & 22.55 & Neral & 29.56 & 34.29 & 31.1 \\
\hline 20. & 22.96 & Geraniol & 3.82 & 1.47 & 2.32 \\
\hline 21 & 23.64 & Geranial & 34.65 & 40.29 & 37.19 \\
\hline 22 & 27.21 & Neryl acetate & 1.75 & 0.82 & 0.96 \\
\hline 23 & 28.51 & $\beta$-Caryophyllene & 1.12 & 1.14 & 1.21 \\
\hline 24 & 29.36 & Isoeugenol & -- & 0.01 & 0.01 \\
\hline 25 & 30.01 & Citronellol & 0.02 & 0.02 & -- \\
\hline 26. & 31.43 & $\mathrm{y}$-Cadinene & 1.09 & 0.62 & 2.01 \\
\hline 27. & 31.45 & Nerol & 0.21 & 0.05 & 0.11 \\
\hline 28. & 31.58 & ס-Cadinene & 0.50 & -- & 0.49 \\
\hline \multirow[t]{2}{*}{29.} & 33.46 & Caryophyllene oxide & 1.03 & 1.10 & 1.08 \\
\hline & & Oil content $(\%)^{*}$ & 91.06 & 93.58 & 90.62 \\
\hline
\end{tabular}

On fresh wt. basis , $\mathrm{t}=$ traces $(<0.10 \%),(-)=$ absent.

camphene(2.47\%) were also detected as major constituents of the plants from $1000 \mathrm{~m}$. The geraniol ( $3.82 \%)$ and nerylacetate $(1.75 \%)$ detected as a major component in $250 \mathrm{~m}$ altitude plants was found low concentration in other altitude plants $(1.47,0.82 ; 2.32,0.96)$. Similarly, citral (isomeric mixture of geranial $(40.29 \%)$, and neral $(34.29 \%)$ ) were the major constituents of $450 \mathrm{~m}$ altitude plant, but these were detected in smaller quantities in $250 \mathrm{~m}$ and $1000 \mathrm{~m}$ altitude plants $(34.65,29.56 ; 37.19,31.10)$. The concentration of various chemical constituents of C.flexuosus from different altitudes is given in Table 2.

\section{DISCUSSION}

Essential oils are generally complex mixtures of compounds, and potential synergistic and antago- nistic effects should be taken into account when evaluating their biological activities (Padalia, et al., 2011, Ganjewala, 2009). The essential oils showed a seasonal and altitudinal discrepancy in the concentrations of their constituents. Therefore, an optimum season and altitude is required for harvesting the essential oil-bearing plants.

As indicated above, the essential oils obtained from C.flexuosus of different altitudes showed significant variation in their chemical composition. The citral content in C. flexuosus plant of mid altitude $(450 \mathrm{~m})$, was found in more concentration than that of the other two altitudes. The essential oil obtained in low altitude $(250 \mathrm{~m})$ contained geraniol, camphene and neryl acetate were detected more in concentration than the oil of high altitude plants, while concentration of $\gamma$-cadinene and $\alpha$ - 
terpineol were increased as the altitude increased. The essential oil of C.flexuosus was evaluated for various biological activities. and showed significant results (Ganjewala and Gupta ,2013). The bioactive potential of essential oil has been attributed to its one or more major chemical constituents namely citral and geraniol. Various chemical constituents are responsible for such activities either individually or synergistically. Since the oil collected from the plants of mid altitude contained linalool, geranial, neral, $\beta$-Caryophyllene, and Caryophyllene oxide constituents in high concentrations, such oils may demonstrated more potent activities i.e. antioxidant activity, antifungal and antibacterial etc. Therefore, the plant of C.flexuosus cultivated at mid altitude may be used for the production of essential oil for commercial purposes.

\section{Conclusion}

The essential of $C$. flexuous owing to their specific aromatic and medicinal properties are used in flavor, fragrance and pharmaceuticals. The pharmacological and medicinal significance of essential oil of this species is due to its constituents, which are mainly monoterpenes with large proportion of citral and geraniol. Despite the immense commercial significance of essential oil, only little work has been done so far towards altitudinal variation of constituents inquantitative and qualitatively. Therefore, we conclude that the C. flexuous cultivated at mid altitude should be used for the production of citral for commercial purposes.

\section{ACKNOWLEDGEMENTS}

This work was supported by UGC, New Delhi, India under the Minor Research Project Grant. Also I duly acknowledge the CIMAP-CSIR research centre, Pantnagar, Uttarakhand, India for providing necessary facilities and support.

\section{REFERENCES}

1. Adams R.P. (1995). Identification of Essential Oil Constituents by Gas Chromatography/Mass Spectroscopy. Allured Publ. Corp., Carol Stream, Illinois.

2. Badoni Ruchi, Semwal, Deepak Kumar and Rawat, Usha (2010),Composition variation of essential oils of Artemisia nilagirica and Artemisia Capillaris, growing in India. Journal of Applied and Natural Science, 2 (1): $30-33$.

3. Bor, N.L. (1960). The Grasses of Burma, Ceylon, India and Pakistan, Pergamon Press, London, P: 767.

4. Davies D.W. (1990). Gas chromatographic retention indices of monoterpenes and sesquiterpenes on methyl silicone and Carbowax 20M phases, J. Chromatograph., 503: 1-24.

5. Ganjewala ,D. (2009) Cymbopogon essential oil : chemical compositions and bioactivities, International journal of essential oil therapeutics, 3: 56-65.

6. Ganjewala ,D. and Gupta, A.K (2013), Lemon grass (Cymbopogon flexuosussteud.) wats essential oil : overview and biological activites, RPMP 37 (II) : 233274.

7. Gupta ,B.K. and Jain, N. (1978). Cultivation and utilization of genus Aromatic Cymbopogon in India, Indian Perfum. 22: 55-68.

8. Khanuja, S.P.S; Shasany, A.K.,Pawar, A.,Lal, R.K. (2005). Essential oil constituents and RAPD markers to establish species relationship in Cymbopogon Spreng. (Poaceae). Biochem. Syst. Ecol. 33:171-186.

9. Kulkarni, R.N., Mallavarapu R.R. and Ramesh S. (1992). The oil content and composition of new variants of C. flexuosus. J. Essent. Oil. Res., 4: 511-514.

10.Kulkarni, R.N., Baskaran, K . and Ramesh S. (2003). Five cycles of recurrent selection for increased essential oil content in East Indian Lemongrass: Response to selection, and effects on heritabilities of traints and inter trait correlation. Plant Breed., 122:131-135.

11.Kumar, S. Dwivedi, S, Kukreja, A.K., Sharma, J,R and Bagchi, G.D. (2000) Cymbopogon: The aromatic Grass Monograph, CIMAP Publication, Lucknow, India.

12.Lawrence B.M. (1988). Progress in essential oil: citronella oil, Perfum. Flav. 23: 80-82.

13.Mathela,C.S., Pant, A.K. ; Melkani A.B. and Pant A. (1986). Aromatic grasses of U.P. Himalaya: a new wild species as a source of aroma chemicals. Sci. Cult. 52: 342-344.

14.Padalia, R.C., verma.R.S., Chanotiya, C.S ., Yadav, A.(2011). Chemical fingerprint of the fragrant volatiles of Nineteen Indian Cultivars of Cymbopogon Spreng. $5(4)$ : 290-99.

15.Rao, B.L. (1997). Scope for Development of New Cultivars of Cymbopogons as a Source of Terpene Chemicals (In: S. S. Handa \& M. K. Kaul (Eds), Supplement to Cultivation and Utilization of Aromatic Plants), National Institute of Science and Communication, New Delhi, India, P: 71.

16.Rao, R.R. (1994), Biodiversity in India (Floristic aspect) Bishan Singh, Mahendra Pal Singh, Dehradun, India, ISBN 8121100100.

17.Rao, B.R.R, Rajput, D.K., and Patel, R.P. (2009). Essential Oil Profiles of Different Parts of Palmarosa (Cymbopogon martini (Roxb.) Wats. Var. motia Burk, J. Essential Oil Res., 21.519-521.

18.Sangwan, N.S., Yadav, U. and Sangwan, R.S., (2001). Molecular analysis of genetic diversity in elite Indian cultivars of essential oil trade types of aromatic grasses (Cymbopogon species). Plant Cell Rep., 20:437-444.

19.Soenarko,S. (1997). The genus Cymbopogon. Reinwardtia 9:225-226.

20.Verma, R.S., Laiq-Ur-Rahman, Verma , R.K., Chauhan, A., Singh. A, Kukreja. A.K., Khanuja, S.P.S. (2009) qualitative performance of Java citronella cultivars in Kumaon Himalaya, J. Med. Arom. PI. Sci., 31, 321-325. 